\title{
Effects of Short-Term Varenicline Administration on Emotional and Cognitive Processing in Healthy, Non-Smoking Adults: A Randomized, Double-Blind, Study
}

\author{
Roel JT Mocking ${ }^{1,2,4}$, C Patrick Pflanz ${ }^{1,3,4}$, Abbie Pringle', Elizabeth Parsons', Sarah F McTavish', \\ Phil J Cowen' and Catherine J Harmer*,' \\ 'University Department of Psychiatry, Warneford Hospital, Oxford, UK; ${ }^{2}$ Department of Psychiatry, Programme for Mood Disorders, Academic \\ Medical Centre, University of Amsterdam, Amsterdam, The Netherlands; ${ }^{3}$ Institute of Neuroscience and Medicine, BSc Programme in Clinical and \\ Experimental Neuroscience, Jülich Research Centre, Institute of Neuroscience and Medicine, University of Cologne, Jülich, Germany
}

\begin{abstract}
Varenicline is an effective and increasingly prescribed drug for smoking cessation, but has been associated with depressive symptoms and suicidal behavior. However, it remains unclear whether those changes in mood and behavior are directly related to varenicline use, or caused by smoking cessation itself or reflects depression and suicidality rates in smokers, independent of treatment. To investigate the influence of varenicline on mood and behavior independent of smoking and smoking cessation, we assessed the effects of varenicline on emotional processing (a biomarker of depressogenic effects), emotion-potentiated startle reactivity, impulsivity (linked with suicidal behavior), and cognitive performance in non-smoking subjects. We used a randomized, double-blind design, in which we administered varenicline or placebo to healthy subjects over 7 days $(0.5 \mathrm{mg} /$ day first 3 days, then $1 \mathrm{mg} /$ day $)$. Cognitive and emotional processing was assessed by a battery of computerized tasks and recording of emotion-potentiated startle response. A total of 4 I subjects were randomized, with 38 subjects included in the analysis. The varenicline group did not differ from placebo in terms of negative biases in emotional processing or mood. However, compared with placebo, the varenicline group scored higher on working and declarative memory. In conclusion, short-term varenicline use did not influence negative biases in emotional processing or impulsivity in non-smoking subjects, thereby not supporting direct depressogenic or suicidal risk behavior-inducing effects. In contrast, varenicline may have cognitive-enhancing effects.

Neuropsychopharmacology (2013) 38,476-484; doi:I0.1038/npp.2012.205; published online 17 October 2012
\end{abstract}

Keywords: smoking cessation; tobacco use cessation products; adverse effects; depression; randomized controlled trial; nicotinic agonists

\section{INTRODUCTION}

Tobacco use, resulting from nicotine addiction, is the single most preventable cause of disease, disability, and death (National Center for Chronic Disease Prevention and Health Promotion, 2011). Varenicline (Chantix, Champix), is the most effective current pharmacological treatment for nicotine addiction (Cahill et al, 2011). Varenicline exerts its effect by binding as partial competitive agonist to $\alpha 4 \beta 2-$ nicotinic acetylcholine (nACh) receptors. Compared with nicotine, varenicline has higher affinity for $\alpha 4 \beta 2-\mathrm{nACh}$ receptors, but only $45 \%$ intrinsic activity (Rollema et al, 2007). Activation of nACh receptors from the $\alpha 4$ receptor

*Correspondence: Dr CJ Harmer, University Department of Psychiatry, Warneford Hospital, Neurosciences Building, Roosevelt Drive, Oxford, Oxon, OX3 7JX, UK, Tel: + 44 I865 22396I, Fax: + 441865251076 E-mail: catherine.harmer@psych.ox.ac.uk

${ }^{4}$ These authors contributed equally to this work.

Received II June 2012; revised 28 August 2012; accepted 29 August 2012 family is sufficient for nicotine-induced reward, tolerance, and sensitization (Tapper et al, 2004), whereas $\beta 2$-containing nACh receptors are primary substrates for nicotine's addictive properties (Picciotto et al, 1998).

$\alpha 4 \beta 2$ Receptors on mesolimbic dopaminergic neurons are crucial for reward and considered responsible for nicotine's addictive potential (Laviolette and van der Kooy, 2004). The partial agonist varenicline competitively blocks nicotine binding to nACh receptors, and has been hypothesized to prevent rewarding effects of nicotine use. In addition, through its moderately stimulating effects, varenicline is expected to decrease nicotine withdrawal symptoms (Cahill et al, 2011).

Despite effectiveness of varenicline in nicotine-dependent patients, varenicline use decreased, because of associations with neuropsychiatric adverse events (Williams et al, 2011). Post-marketing surveys have reported associations between varenicline and depression, aggression and suicidal ideation (Medicines and Healthcare Products Regulatory Agency, 2008), which led to a boxed warning by the FDA.

However, because $30-40 \%$ of smokers have psychological disorders (Lawrence et al, 2009), and smoking cessation 
can lead to depression (Covey et al, 1990), it is not clear whether these adverse effects can be explained by smoking and/or smoking cessation itself. Placebo-controlled trials of varenicline reported associations of varenicline with sleep disorders, but found no association with serious psychiatric adverse events (Garza et al, 2011; Tonstad et al, 2010; Cahill et al, 2011; Hong et al, 2011). However, these trials were underpowered to detect rare-but serious-adverse events (O’Malley, 2011).

There is no known pharmacological explanation of how varenicline treatment would cause depressogenic adverse events. On the contrary, being a partial nACh receptor agonist, varenicline could reduce cholinergic system hyperactivity hypothesized in depression (Patterson et al, 2009; Philip et al, 2009). Indeed, in contrast to reported adverse psychiatric events, varenicline has been discussed as potential antidepressant (Philip et al, 2010; Mineur and Picciotto, 2010).

In addition, varenicline increased n-back task performance among abstinent smokers (Loughead et al, 2010), consistent with cognitive-enhancing effects of central cholinergic drugs including (A)Ch-esterase inhibitors donepezil and rivastigmine (Ginani et al, 2011; Rokem et al, 2010). Although their cholinergic effects are, in contrast to varenicline, not selective to nACh receptors, it could be hypothesized that varenicline has similar cognitive-enhancing effects.

As reports of neuropsychiatric adverse effects limit varenicline's potential to treat nicotine addiction and its associated health risks, it is important to investigate whether these effects are caused by varenicline or ceasing smoking itself. This could be achieved by investigating varenicline's effects in non-smoking individuals, thereby eliminating any possible bias by smoking status.

Studies specifically designed to induce serious adverse events by varenicline in healthy non-smoking subjects would cause ethical and power issues. Using predictive biomarkers of depressogenic and suicide risk-enhancing effects might help overcome these issues. Negative biases in emotional processing are common in depression and are believed to have an important role in its pathophysiology (Harmer et al, 2011). These biases may serve as early and sensitive predictors of drug-induced emotional changes and depressogenic effects (Pringle et al, 2011a; Harmer et al, 2011). For example, depressogenic effects of rimonabant and tryptophan depletion are reflected by observations of negative biases in emotional processing (Hayward et al, 2005; Horder et al, 2012) despite absence of subjective mood changes.

Furthermore, cholinergic modulations-particularly of $\alpha 4 \beta 2$-nACh receptors (Tsutsui-Kimura et al, 2010)-have been linked to impulsivity (Ohmura et al, 2012). In general, antagonists reduce, whereas agonists increase impulsive behavior (Ohmura et al, 2012), but this effect might be modulated by baseline impulsivity (Potter et al, 2012). Consequently, we were interested whether varenicline might affect impulsivity, associated with suicide risk (Ohmura et al, 2012).

Therefore, aims of our study were to test the hypotheses that varenicline in non-smoking individuals would (I) induce negative biases in emotional processing, (II) increase impulsivity, and (III) enhance cognitive performance.

\section{PATIENTS AND METHODS}

\section{Participants}

We recruited non-smoking participants using posters and web-advertisements. To exclude possible biases by (previous) nicotine use, we excluded subjects currently or previously using any form of tobacco.

Participants had to be aged 18-35, and physically fit (assessed by qualified medical doctors, eg, using electrocardiography) with a body mass index of $18.5-30 \mathrm{~kg} / \mathrm{m}^{2}$. We screened subjects using the Structured Clinical Interview for DSM-IV Axis I Disorders (First et al, 1997) and excluded subjects with personal and/or family histories of drug and/or alcohol dependency, psychiatric illnesses or suicidal ideation or acts, thereby minimizing risk of adverse events for ethical reasons. We excluded subjects who were taking psychotropic medication, or had taken part in studies involving medication or used recreational drugs within the last 3 months. To avoid retest effects, we excluded participants who had taken part in studies involving the emotional test battery (ETB).

Participants gave written informed consent. The study was reviewed by the Berkshire Research Ethics Committee (10/H0505/26). Participants received $£ 125$ reimbursement for participation.

\section{Procedure}

In this double-blind study, we randomized participants to receive either 10 capsules of $0.5 \mathrm{mg}$ varenicline tartrate (manufactured by Pfizer Pharmaceuticals; intervention), or placebo (lactose pills; control), identically packed to assure blinding.

We administered the capsules for 7 days, using titration as recommended by the manufacturer. For the first 3 days and the 7th day, we instructed participants to take 1 capsule at 0800 hours, for days 4-6 we instructed participants to take an additional capsule at 2000 hours. We used this lower dose than the manufacturer's recommended $1 \mathrm{mg}$ twice daily (BID) for several reasons: (I) taking $0.5 \mathrm{mg}$ BID is predicted to yield $60 \%$ of steady-state kinetics that would be achieved using $1 \mathrm{mg}$ BID (Faessel et al, 2010), (II) varenicline is still therapeutically effective at these doses with only slightly lower abstinence rates (Oncken et al, 2006), and (III) manufacturer's recommended dose is intended for smokers, and could give rise to tolerability issues in our non-smoking population (Faessel et al, 2006). We asked subjects to refrain from alcohol and recreational drugs during the study period and from caffeine on the test day.

\section{Measures}

Subjective ratings. At baseline, we asked participants to fill in the Beck depression inventory (BDI; Beck et al, 1996) to assess subjective mood; state trait anxiety inventory (STAI; Spielberger et al, 1983) to assess feelings of anxiety; Eysenck personality questionnaire (EPQ; Eysenck and Eysenck 1975) to assess personality traits; Befindlichkeits scale (BFS; von Zerssen and Petermann 2011) to investigate mood and energy; positive and negative affective schedule (PANAS; Crawford and Henry 2004); visual analog scales (VAS) to assess nausea, dizziness, hunger, anxiety, 
happiness, sadness, and alertness; and side effect questionnaires to assess nausea, headache, insomnia, odd dreams, drowsiness, fatigue, dizziness, xerostomia, vomiting, and diarrhea. On days 1-7, participants repeated the BFS, PANAS, VAS, and side effect questionnaires each morning before taking the capsule. In addition, participants repeated the BDI, VAS, BFS, PANAS, and STAI before testing.

Emotional test battery. On day 7, we tested participants from 1000 to 1330 hours using computer-based tasks. The P1vital Oxford ETB detects biases in cognitive emotional processing, thereby serving as early and sensitive predictive biomarker for antidepressant (Harmer et al, 2011), but also depressogenic effects (Horder et al, 2012). The ETB consists of three subtasks: the facial expression recognition task (FERT), word categorization and memory, and dot probe task (DPT).

A detailed description is provided elsewhere (Harmer et al, 2011). In brief, the FERT featured 250 stimuli consisting of six basic emotions (happiness, surprise, sadness, fear, anger, and disgust) from the pictures of affect series (Ekman and Friesen 1976), morphed in variable intensity and presented for $500 \mathrm{~ms}$. We instructed participants to quickly and accurately classify each facial emotion, and measured accuracy and reaction times.

In the word categorization and memory task, we presented 60 matched disagreeable or agreeable personality characteristic words for $500 \mathrm{~ms}$. We asked participants to categorize words as likeable or dislikeable when overhearing someone referring to them as possessing this characteristic. Immediately following this task, we asked participants to recall and write down as many words from the task as possible in $2 \mathrm{~min}$. Subsequently, we measured recognition memory using a computerized task consisting of 60 target words and 60 matched distracters. Outcome variables included number and valence of correctly categorized words, correctly and falsely recalled words, correctly recognized words, distractors falsely/correctly recognized as (un)familiar, and categorization and recognition reaction times.

For the DPT, we presented 60 socially threateningneutral, 60 positive-neutral, and 60 neutral-neutral vertical matched word pairs after a fixation cross. In the unmasked condition, word pairs were presented for $500 \mathrm{~ms}$ and then a probe (either one or two stars) appeared in the location of one of the preceding words. We asked participants to press a button to indicate the number of stars. In the masked condition, sequence of events was identical, except after $14 \mathrm{~ms}$ word pairs were followed by a mask (constructed from digits, letters and non-letter symbols, eg, @B\%2\#, matched for word position and length) for $186 \mathrm{~ms}$. We calculated vigilance reaction times as differences between congruent (probes appeared in the position of the emotional word) and in-congruent (probes appeared in the opposite position to the emotional word) trials.

Emotion-potentiated startle task (electromyography). A detailed description is provided elsewhere (Pringle et al, 2011b). Concisely, after a habituation session, we presented 63 pictures of different valence (pleasant, unpleasant, and neutral), taken from the International Affective Picture
Scale (gender specified; Larson et al, 2000), for $13 \mathrm{~s}$ followed by a picture with different valence, on a computer screen in three blocks in fixed order. We recorded the eye-blink component of startle reflexes using three lead electromyography (EMG startle response system, San Diego Instruments, San Diego, CA). Acoustic probes were $50 \mathrm{~ms}, 95 \mathrm{~dB}$ bursts of white noise, delivered binaurally through headphones at 1.5, 4.5, or $7.5 \mathrm{~s}$ following picture onset (Pringle et al, 2011b). We calculated eye-blink reflex magnitudes and $z$-transformed those to normalize data and reduce intersubject variability.

Impulsivity. We used the continuous performance immediate memory task (IMT) to measure attention, memory, and impulsive behavior (Dougherty et al, 2002), thought to be linked to suicidal behavior (Ohmura et al, 2012). A sequence of six-digit numbers appeared on the screen for $500 \mathrm{~ms}$ each. We instructed participants to click when the displayed number was identical to the one immediately preceding it. Measurements included correct detections (hits), commission errors (false alarms), and latencies (weighted reaction times).

Cognitive tasks. We used a continuous performance n-back task (adapted from Mannie et al, 2010) to measure working memory, with three levels of increasing difficulty: 1-, 2-, 3-back tasks. We instructed subjects to indicate whether letters presented on the screen (target) matched a previously presented letter (cue). We presented letters as pseudo-random sequences and instructed subjects to ignore case. Subjects also performed a sensorimotor control task (0-back) during which we requested them to respond to a prespecified letter $(\mathrm{x}, \mathrm{X})$.

The Rey auditory verbal learning test (RAVLT) assesses verbal learning, recall, and recognition (Rey, 1964). The learning session consisted of five trials, during which subjects had to listen to a word list and then repeat as many words as possible in any order. We tested immediate recall after subjects had learnt a second word list and delayed recall after $20 \mathrm{~min}$. We used a list with 30 words (15 targets, 15 distractors) to assess word recognition.

Tasks were completed in the following order: ETB, n-back, RAVLT, IMT, RAVLT continued.

Statistics. We analyzed data with IBM SPSS 19 using repeated-measures analysis of variance (RMANOVA), independent and paired samples $t$-tests, and MannWhitney $U$-tests as appropriate. For selected outcome variables, we calculated target sensitivities $\left(d^{\prime}\right)$ and response biases $(\beta)$ using the following formulas: $d^{\prime}=0.5+((y-$ $x)(1+y-x) / 4 y(1-x))$ with $0<d^{\prime}<1$, where higher values indicate increased accuracy, and $\beta=y(1-y)-x(1-x) /$ $y(1-y)+x(1-x)$ with $-1<\beta<1$, where higher values indicate conservative response style (few false alarms), and $x$ is probability of false alarms (number of false alarms/ number of distracters), whereas $y$ is probability of hits (number of hits/number of targets; Grier, 1971).

We used a priori power calculation to determine required sample size. Based on previous behavioral studies (Horder et al, 2012; Harmer et al, 2011), 40 participants would have been needed to achieve a power of 0.9 to detect a medium 
effect size $f=0.25$ (RMANOVA, two groups, $\geq 2$ repeated measurements, $\alpha=0.05$, correlation among repeated measures $=0.55 ; \mathrm{G}^{\star}$ Power 3.1.3).

\section{RESULTS}

Of 41 included participants, 21 were randomized and allocated to receive varenicline and 20 placebo. Two participants in the varenicline group $(<10 \%)$ withdrew from the study because of side effects (flu-like symptoms $(N=1)$ and nausea $(N=1))$. One subject in the varenicline group had to be excluded because of missing data (Figure 1). Thus, 38 participants were included in the data analysis (varenicline, $N=18$; control $N=20$ ).

Age and sex did not differ significantly between the two groups (Table 1).

\section{Subjective Rating}

There were significant differences in the BDI, EPQ, PANAS, BFS, or STAI neither before, nor during treatment (all $p>0.14$; Table 1 ).

For the VAS, no significant differences were found, except for higher nausea scores in the varenicline group $\left(\mathrm{F}_{1,36}=7.652, p=0.009\right)$.

\section{Emotional Test Battery}

Facial expression recognition task. A RMANOVA showed neither a significant treatment $\times$ emotion interaction, nor a main treatment-effect on target sensitivity $\left(\mathrm{F}_{6,216}=0.746\right.$, $p=0.548 ; \mathrm{F}_{1,36}=0.978, p=0.329$, respectively).

A RMANOVA showed a significant treatment $\times$ emotion interaction for reaction times $\left(\mathrm{F}_{6,216}=2.986, p=0.026\right)$. Independent samples $t$-tests for each emotion separately revealed significantly slower responses in the varenicline group to neutral faces $\left(t_{35}=2.147, p=0.039\right)$.

Word categorization and memory task. No treatment $\times$ emotion interaction for accuracy score was observed in the emotional categorization task $\left(\mathrm{F}_{1,36}=0.157, p=0.695\right)$. A RMANOVA showed no differences between treatment in terms of reaction times $\left(\mathrm{F}_{1,36}=0.808, p=0.375\right)$.

The emotional recall task showed no significant interaction between treatment and emotion for number of correctly recalled words $\left(\mathrm{F}_{1,36}=0.581, p=0.451\right)$, and no main effect of treatment on performance regardless of emotion $\left(F_{1,36}=0.172, p=0.68\right)$.

The emotional recognition task showed no significant treatment $\times$ emotion interaction for percentage of correctly identified words $\left(F_{1,36}=0.001, p=0.978\right)$. However, a trend was observed for a main effect of treatment on accuracy $\left(F_{1,36}=3.796, p=0.059\right)$. $T$-tests showed that the varenicline group recognized significantly more positive words $\left(t_{36}=2.162, p=0.037\right.$, Cohen's $\left.d=3.0731\right)$.

The emotional recognition task showed a significant treatment $\times$ emotion interaction for reaction times $\left(F_{1,36}=5.974, \quad p=0.020\right)$, with faster responses in the varenicline group to correctly recognize positive personality (mean $=1326.77 \mathrm{~ms}, \mathrm{SD}=266.11)$ vs negative personality

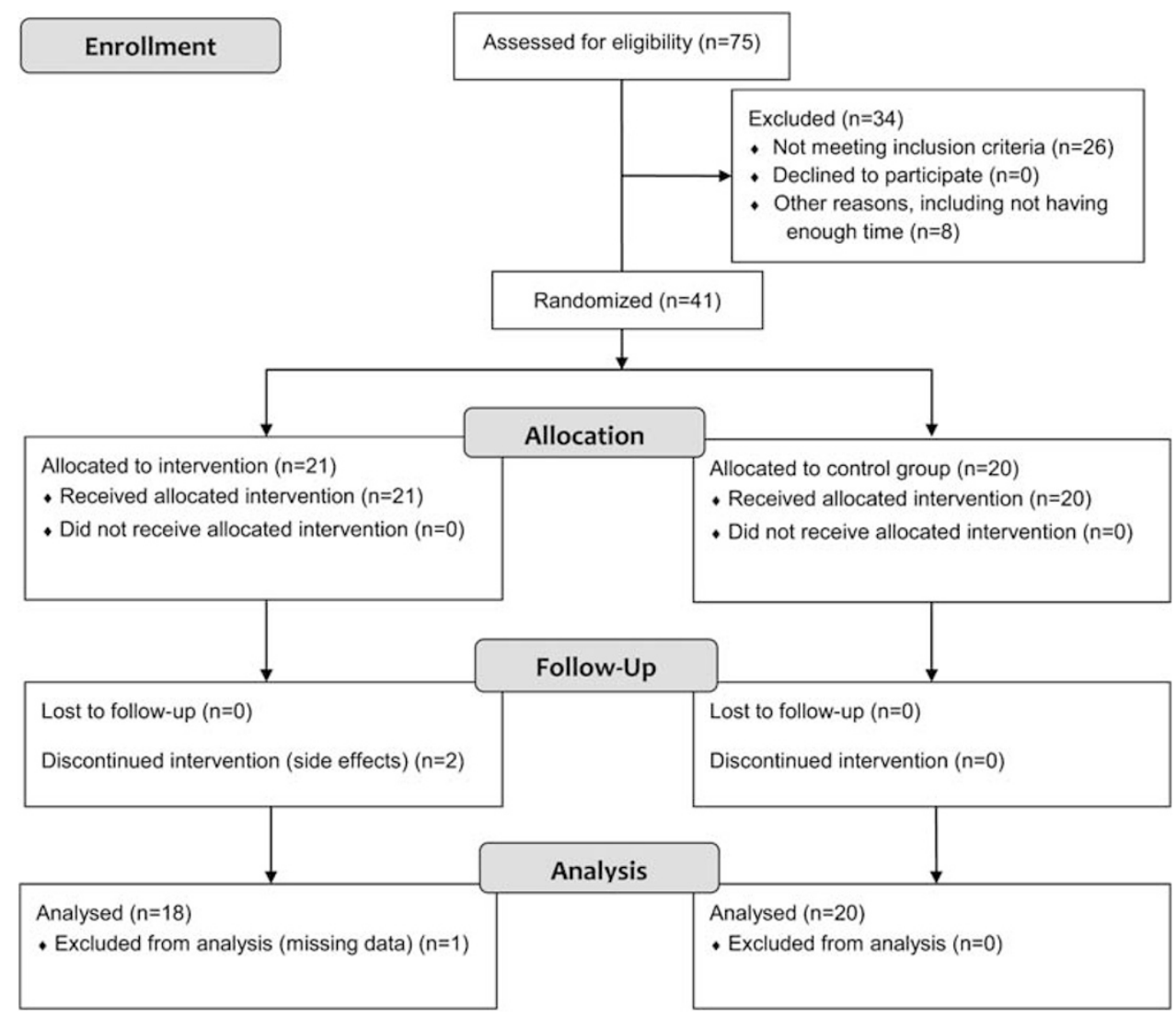

Figure I Participant flow. Participant flow chart and drop-out (based on a template from Consort 20 I0). 
Table I Subject Characteristics

\begin{tabular}{lccc}
\hline & $\begin{array}{c}\text { Varenicline } \\
(\mathbf{N}=\mathbf{I 8})\end{array}$ & $\begin{array}{c}\text { Placebo } \\
\mathbf{( N = 2 0 )}\end{array}$ & $\begin{array}{c}\boldsymbol{p} \text { - } \\
\text { Value }\end{array}$ \\
\hline Age (years), mean \pm SD & $22.4 \pm 4.33$ & $22.7 \pm 2.98$ & 0.864 \\
$\begin{array}{l}\text { Sex, \% female } \\
\text { Occupation, \% }\end{array}$ & 55.6 & 50.0 & 0.732 \\
$\quad$ PhD)-student & 88.9 & & 0.485 \\
$\quad$ Other & 11.1 & 95.0 & \\
$\begin{array}{l}\text { Body weight (kg), } \\
\text { mean } \pm \text { SD }\end{array}$ & $66.29 \pm 10.46$ & $66.68 \pm 6.92$ & 0.894 \\
$\begin{array}{l}\text { Body mass index, } \\
\text { mean } \pm \text { SD }\end{array}$ & $22.8 \pm 2.33$ & $22.6 \pm 1.96$ & 0.782 \\
$\begin{array}{l}\text { BDI baseline, mean } \pm \text { SD } \\
\text { BDI endpoint, mean } \pm \text { SD }\end{array}$ & $2.00 \pm 3.53$ & $1.80 \pm 2.10$ & 0.833 \\
\hline
\end{tabular}

Abbreviation: $\mathrm{BDI}$, Beck depression inventory.

(mean $=1485.54 \mathrm{~ms}, \mathrm{SD}=285.81)$ characteristic words (placebo group, positive words: mean $=1362.45 \mathrm{~ms}, \mathrm{SD}=$ 338.96, negative words: mean $=1387.27 \mathrm{~ms}, \mathrm{SD}=276.17$ ).

Dot probe. A three-way treatment $\times$ valence $\times$ mask RMANOVA was used to analyze reaction times. Treatment $\times$ valence $\left(\mathrm{F}_{1,36}=1.267, p=0.268\right)$ and mask $\times$ treatment $\left(\mathrm{F}_{1,36}=0.556, p=0.461\right)$ interactions were not significant. However, a trend existed for the three-way treatment $\times$ valence $\times$ mask interaction $\quad\left(F_{1,36}=3.222\right.$, $p=0.081)$. Analyzing masking conditions separately, the valence $\times$ treatment interaction was significant for the unmasked condition $\left(\mathrm{F}_{1,36}=4.452, p=0.042\right)$, but not for the masked condition $\left(\mathrm{F}_{1,36}=0.377, p=0.543\right)$. During the unmasked condition, the varenicline group showed reduced vigilance in response to negative compared with positivepairs compared with placebo, although individual post hoc tests failed to reach significance (negative: $t_{36}=-1.701$, $p=0.100$; positive: $t_{36}=1.527, p=0.149$ )

\section{Emotion-Potentiated Startle Task}

A trend toward a treatment $\times$ valence interaction existed $\left(\mathrm{F}_{2,50}=2.955, p=0.061\right.$; Figure 2$)$. In addition, there was a treatment main-effect, with significantly decreased magnitudes of startle response $\mathrm{z}$-scores in the varenicline group $\left(\mathrm{F}_{1,25}=4.343, p=0.048\right)$. Post hoc $t$-tests for each valence separately showed that the between-subject effect was mainly driven by decreased responses to neutral pictures in the varenicline group compared with placebo $\left(t_{25}=2.807\right.$, $p=0.010)$. Differences in startle reflexes for other valences were nonsignificant $(p>0.252)$. Post hoc paired samples $t$-tests showed significant differences in startle reflexes to unpleasant and neutral pictures in the varenicline group, with lower responses to neutral pictures $\left(t_{11}=2.492\right.$, $p=0.030)$. Differences between other valences and all comparisons in the placebo group were nonsignificant $(p>0.135)$. This suggests that the trend of a treatment $\times$ valence interaction was also mainly caused by decreased startle reflexes to neutral pictures in the varenicline group.

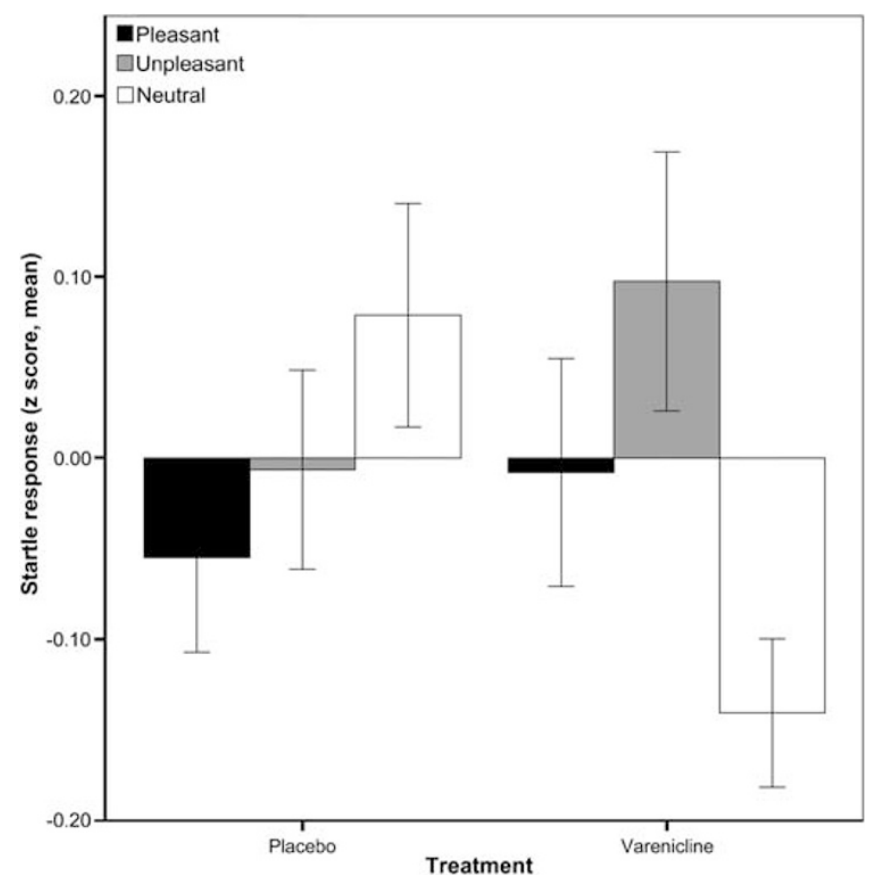

Figure 2 Mean z-scores of startle reactivity for pleasant, unpleasant, and neutral stimuli among non-smoking healthy subjects after 7 day randomized treatment with placebo $(N=20)$ or varenicline $(N=18)$. Error bars represent SEM.

\section{Impulsivity}

Immediate memory task. Two participants were excluded from analyses because of technical difficulties. There was no significant difference in target sensitivity $\mathrm{d}^{\prime}\left(t_{34}=0.497\right.$, $p=0.622)$ and response bias $\beta\left(t_{34}=-1.113, p=0.273\right)$. In addition, Mann-Whitney $U$-tests showed no differences for $\mathrm{A}^{\prime}(p=0.537)$ and $\mathrm{B}^{\prime \prime} \mathrm{d}(p=0.646)$. A RMANOVA showed no treatment $\times$ latency interaction $\left(F_{1,34}=0.970, p=0.332\right)$.

\section{Cognitive Tests}

$N$-back. One participant performed at chance level during the sensorimotor control task (0-back), and was therefore excluded from subsequent analysis. There was a significant interaction between treatment and percentage of correct trials $\left(F_{3,105}=3.43, p=0.035\right)$. Post hoc tests showed that this effect was only significant in the most difficult condition (3-back), with more hits in the drug group $(p=0.02$, Cohen's $d=0.71$; Figure 3$)$.

Rey auditory verbal learning test. One participant in the varenicline group was excluded because of incomplete data. A RMANOVA $\left(\mathrm{F}_{4,140}=1.375, p=0.256\right)$ showed no interactions between treatment and percentage of remembered words in the AVLT learning session.

However, there was a significant treatment $\times$ number of recalled words interaction in the immediate and delayed memory task, measured as percentages of learning scores $\left(\mathrm{F}_{1,35}=7.867, p=0.008\right)$. In addition, there was a trend for a main effect of treatment on number of recalled words $\left(\mathrm{F}_{1,35}=3.564, p=0.067\right)$. Pairwise comparisons showed that the varenicline group remembered significantly more words compared with placebo in the delayed memory task 


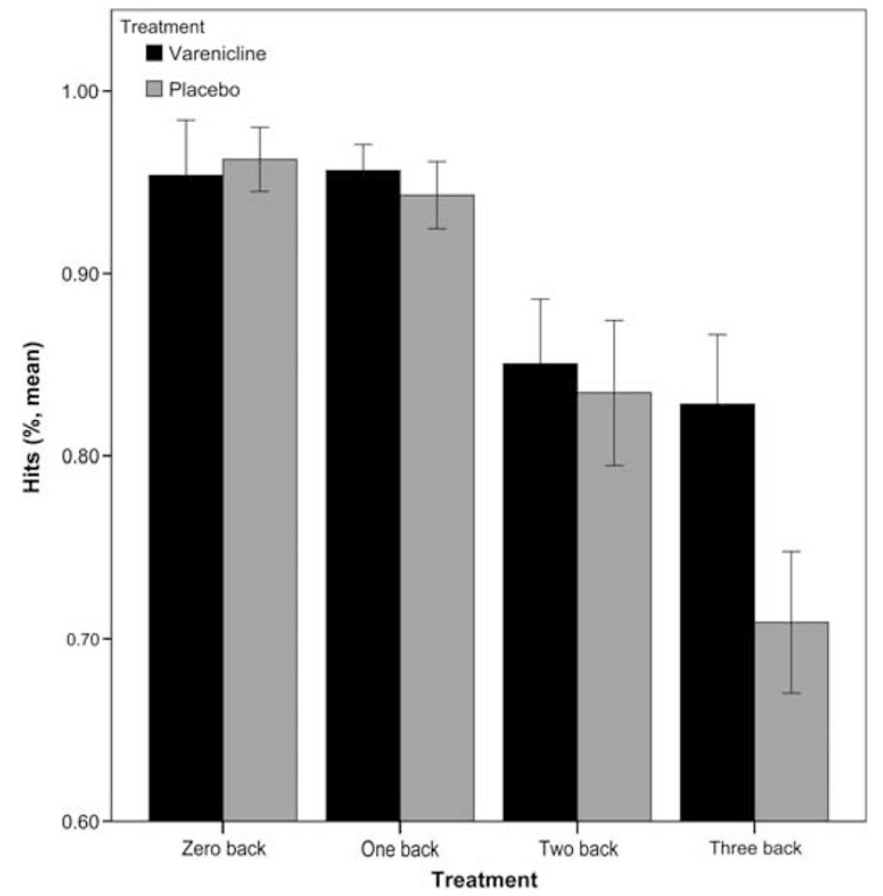

Figure 3 Mean percentage of correctly remembered letters ('hits') in four parts of the n-back task with increasing difficulty among non-smoking healthy subjects after 7 day randomized treatment with placebo $(N=20)$ or varenicline $(N=18)$. Error bars represent SEM.

$(p=0.015$, Cohen's $d=3.75)$, but not in the immediate memory task (Figure 4).

Data from the recognition task showed no significant differences (Target sensitivity $d^{\prime}: t_{35}=0.442, p=0.662, \beta$ : $\left.t_{35}=-0.364, p=0.714\right)$.

\section{DISCUSSION}

The present study aimed to investigate the influence of varenicline on (I) emotional processing, (II) impulsivity, and (III) cognitive performance. In a double-blind, randomized study-design, non-smoking participants received varenicline or placebo for 7 days. Subsequently, participants performed several psychological tasks, including the ETB and emotion-potentiated startle (biomarkers of depressogenic effects), IMT (impulsivity as a risk factor for suicidal behavior), $\mathrm{n}$-back tasks (working memory), and the auditory and verbal learning test (declarative memory). Results show that varenicline has little effect on emotional processing or impulsivity in healthy adults, thereby not suggestive of depressogenic or undesired psychological effects. On the contrary, a trend toward enhanced processing of positive emotional information has been found. In addition, results suggest a cognitive-enhancing effect for varenicline.

The ETB has been previously used as biomarker of antidepressant and depressogenic effects of pharmacological agents. In particular, although drug treatments for depression enhance recall of positive versus negative selfreferent cues (Harmer et al, 2011), depressogenic manipulations tend to have opposite effects (Hayward et al, 2005; Horder et al, 2012). In the present study, there was no

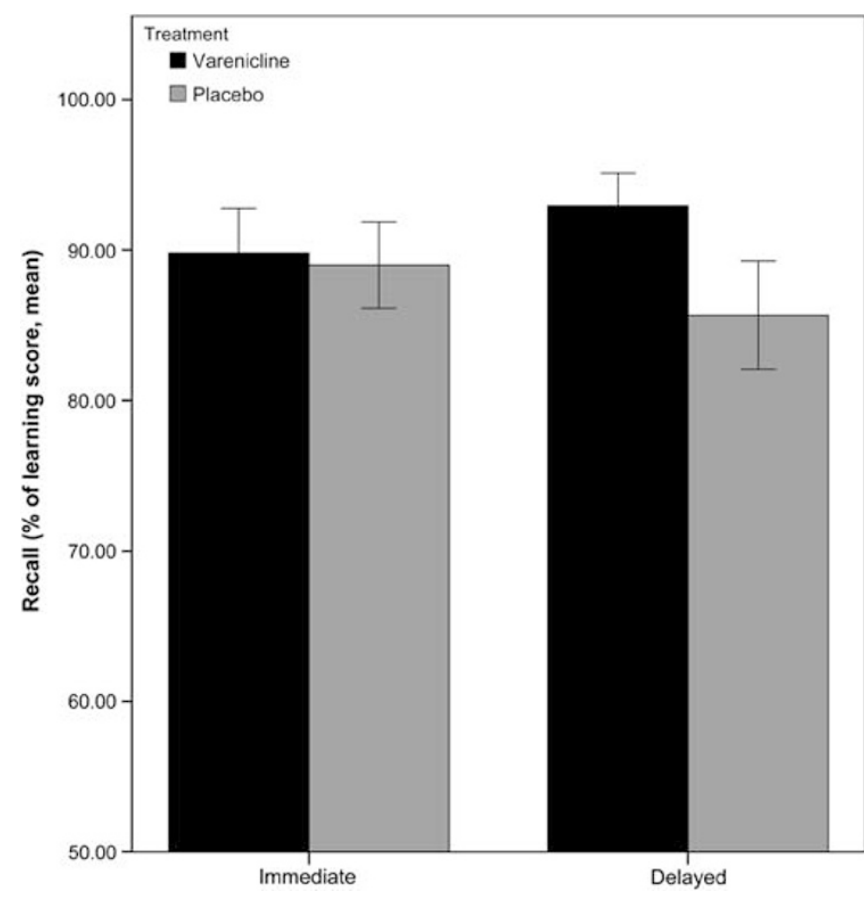

Figure 4 Recalled words as percentages of learning scores in the Rey auditory verbal learning test (RAVLT) among non-smoking subjects after 7 day randomized treatment with placebo $(N=20)$ or varenicline $(N=18)$. Error bars represent SEM.

evidence that one week administration of varenicline led to negative emotional biases compared with double-blind administration of placebo. On the contrary, varenicline had a small, but statistically significant, positive effect on emotional processing in the emotional categorization and recognition task. Results from the emotion-potentiated startle suggest that varenicline reduces eye-blink startle responses, consistent with a previous report of reduced startle reactivity in patients with schizophrenia following varenicline administration (Hong et al, 2011). These results are more consistent with previous research, which suggests potential antidepressant activity (Patterson et al, 2009; Philip et al, 2009; Mineur and Picciotto, 2010), than data suggesting depressogenic effects.

Although present study's results do not suggest depressogenic effects or changes in impulsivity, recent post-marketing surveillance studies reported associations between varenicline and depression and suicidal/self-injurious behavior (Moore et al, 2011; Harrison-Woolrych and Ashton, 2011). However, randomized clinical trial data did not show this influence of varenicline (Cahill et al, 2011; Garza et al, 2011; Hong et al, 2011, Tonstad et al, 2010).

How could these discrepancies between our study, trial data, and cohort studies be explained? Cohort studies can be subject to several forms of biases, including stimulated reporting through media awareness (Moore et al, 2011). Placebo-controlled trials exclude these biases, but do not have enough power to detect rare side effects (O'Malley, 2011). The present study did not use depressive symptoms or suicidal behavior as an outcome, but rather predictive depressogenic biases in emotional processing and impulsivity. In contrast to the drug rimonabant (Horder et al, 2012), results of the present study do not suggest 
depressogenic or suicidal behavior risk-inducing effects of varenicline in healthy non-smoking subjects.

These findings could have several reasons. First, reported associations between varenicline use and depression and suicide could result from bias, and are therefore not observed in this and other placebo-controlled trials. Second, varenicline could exert its potential depressogenic effects through pathophysiological mechanisms not measured in the present study. Third, the potential depressogenic effects of varenicline could occur only in interaction with smoking cessation, and were therefore not observed in the present study's non-smoking population. Fourth, varenicline could only be potentially depressogenic in subjects at risk (eg, with a (family) history of depression), who were excluded in our study. To clarify these issues, future adequately powered studies should investigate differential effects of varenicline administration on emotional processing in abstinent smokers and smokers who relapsed during smoking cessation.

Although the present study does not suggest any influence of varenicline on emotional processing or impulsivity, it showed cognitive-enhancing effects of varenicline on working and episodic declarative memory tasks, characteristic of cholinergic agents (Ginani et al, 2011; Rokem et al, 2010). As varenicline has no affinity for muscarinic receptors, the cognitive-enhancing effect of cholinergic agents may be at least partially mediated by $\mathrm{nACh}$ receptors. Besides through activation of the $\alpha 4 \beta 2$ subtype, this could also be due to varenicline's full agonist properties at the $\alpha 7$ subtype (Loughead et al, 2010).

Similarly, varenicline increased activity in brain areas related to working memory and performance in the n-back task (Loughhead et al, 2010). This cognitive-enhancing property may alleviate cognitive deficits experienced as withdrawal effects during nicotine abstinence, thereby contributing to its therapeutic effect in smoking cessation. Indeed, deficits in working memory predict relapse after short nicotine abstinence (Patterson et al, 2010). Similarly, cognitive enhancers are suggested in the treatment of other addictions (Sofuoglu, 2010). In addition, varenicline's cognitive-enhancing effect might be therapeutically useful in patients with cognitive impairments (Cocores and Gold, 2008).

Some limitations of the study merit discussion. First, only half of the usually used dose $(2 \mathrm{mg})$ was given for a relatively short period. As described in the Patients and methods section, a balance had to be sought between safe and tolerable doses in a non-smoking population and adequate simulation of therapeutically effective doses. Taking $0.5 \mathrm{mg}$ BID is predicted to yield $60 \%$ of steady-state kinetics that would be achieved using $1 \mathrm{mg}$ BID (Faessel et al, 2010), which has been shown to be almost equally effective (Oncken et al, 2006). Furthermore, drop-outsoccurring only in the varenicline group-suggest that the selected dose was at the upper tolerability limit for nonsmokers. In addition, the ETB has been shown to be a sensitive and early biomarker of potential (anti-)depressogenic effects, also able to detect effects after acute treatments or even single doses (Harmer et al, 2011). Therefore, we believe it is unlikely that effects only apparent at higher and longer administered dosages might have remained undetected. Second, multiple tests were used to investigate hypotheses. However, because for the first two hypotheses results led to falsification, this would not change by correction for multiple testing. For the third hypothesis on cognitive performance we used two tasks, and results showed a consistent pattern of medium to large effect sizes. Third, because the majority of participants were students, who have a high proficiency level in cognitive tasks, the cognitive-enhancing effect might be underestimated because of ceiling effects. Finally, nicotine abstinence was ascertained verbally; no drug screens have been utilized.

Nevertheless, the present study also had strengths. By studying never-smoking subjects, we could assess the influence of varenicline unconfounded from any bias by current and/or previous smoking status. In addition, the ETB may provide an early predictive (before subjective mood ratings change) and sensitive measurement for druginduced emotional changes and depressogenic effects (Pringle et al, 2011a; Harmer et al, 2011), thereby surpassing ethical and power issues that would occur when actual adverse events would have been measured.

In conclusion, 7 days varenicline treatment in healthy non-smoking subjects did not negatively influence mood or impulsivity, thereby not suggestive of depressogenic or suicidal behavior. In contrast, varenicline increased accuracy scores in memory tasks, consistent with enhanced cognitive performance. Trials in other populations combined with results from post-marketing surveys are needed to determine whether risk for serious adverse neuropsychiatric events should limit varenicline's potential to treat nicotine addiction, and thereby reduce the tobacco use associated health impact.

\section{ACKNOWLEDGEMENTS}

We are most grateful to the participants of our study. Funding support for this study was provided by the Medical Research Council G0801432/1. Study's funding sources had no role in the study design; collection, analysis, and interpretation of data; writing of the report; and decision to submit the paper for publication. The corresponding author had full access to all the data and had final responsibility for the decision to submit for publication.

\section{DISCLOSURE}

$\mathrm{CJH}$ serves on the advisory board of P1vital, and receives consultancy fees from and has shares in the company; and is also a director of Oxford Psychologists. PJC has been a paid member of advisory boards of Eli Lilly, Lundbeck and Servier, and has received remuneration for scientific advice given to legal representatives of GlaxoSmithKline. The remaining authors declare no conflict of interest.

\section{Author Contributions}

AP, PJC, and CJH designed the study. RJTM, CPP, AP, EP, and SFM collected the data. RJTM, CPP, AP, and EP analyzed the data. RJTM and CPP drafted the manuscript. All authors participated in interpretation of the final results and editing of the report. All authors saw and approved the final version of the report. 


\section{REFERENCES}

Beck AT, Steer RA, Ball R, Ranieri W (1996). Comparison of Beck depression inventories -IA and -II in psychiatric outpatients. J Pers Assess 67: 588-597.

Cahill K, Stead LF, Lancaster T (2011). Nicotine receptor partial agonists for smoking cessation. Cochrane Database Syst Rev 16: CD006103.

Cocores JA, Gold MS (2008). Varenicline and adult ADHD. J Neuropsychiatry ClinNeurosci 20: 494-495.

Covey LS, Glassman AH, Stetner F (1990). Depression and depressive symptoms in smoking cessation. Compr Psychiatry 31: $350-354$.

Crawford JR, Henry JD (2004). The positive and negative affect schedule (PANAS): construct validity, measurement properties and normative data in a large non-clinical sample. $\mathrm{Br} \mathrm{J}$ Clin Psychol 43(Pt3): 245-265.

Dougherty DM, Marsh DM, Mathias CW (2002). Immediate and delayed memory tasks: a computerized behavioral measure of memory, attention, and impulsivity. Behav Res Methods Instrum Comput 34: 391-398.

Ekman P, Friesen WV (1976). Pictures of Facial Affect. Consulting Psychologists Press: Palo Alto, CA.

Eysenck HJ, Eysenck SBG (1975). Manual of the Eysenck personality questionnaire. Hodderand Stoughton, London.

Faessel HM, Smith BJ, Gibbs MA, Gobey JS, Clark DJ, Burstein AH (2006). Single-dose pharmacokinetics of varenicline, a selective nicotinic receptor partial agonist, in healthy smokers and nonsmokers. J Clin Pharmacol 46: 991-998.

Faessel HM, Obach RS, Rollema H, Ravva P, Williams KE, Burstein $\mathrm{AH}$ (2010). A review of the clinical pharmacokinetics and pharmacodynamics of varenicline for smoking cessation. Clin Pharmacokinet 49: 799-816.

First MB, Spitzer RL, Gibbon M, Williams JB (1997). User's guide for the Structured Clinical Interview for DSM-IV Axis I Disorders SCID-I: Clinician Version. American's Psychiatric Publishing: Arlington.

Garza D, Murphy M, Tseng LJ, Riordan HJ, Chatterjee A (2011). A double-blind randomized placebo-controlled pilot study of neuropsychiatric adverse events in abstinent smokers treated with varenicline or placebo. Biol Psychiatry 69: 1075-1082.

Ginani G, Tufik S, Bueno O, Pradella-Hallinan M, Rusted J, Pompéia S (2011). Acute effects of donepezil in healthy young adults underline the fractionation of executive functioning. J Psychopharmacol 25: 1508-1516.

Grier JB (1971). Nonparametric indexes for sensitivity and bias: computing formulas. Psychol Bull 75: 424-429.

Harmer CJ, Cowen PJ, Goodwin GM (2011). Efficacy markers in depression. J Psychopharmacol 25: 1148-1158.

Harrison-Woolrych M, Ashton J (2011). Psychiatric adverse events associated with varenicline: an intensive postmarketing prospective cohort study in New Zealand. Drug Saf 34: 763-772.

Hayward G, Goodwin GM, Cowen PJ, Harmer CJ (2005). Low-dose tryptophan depletion in recovered depressed patients induces changes in cognitive processing without depressive symptoms. Biol Psychiatry 57: 517-524.

Hong LE, Thaker GK, McMahon RP, Summerfelt A, Rachbeisel J, Fuller RL et al (2011). Effects of moderatedose treatment with varenicline on neurobiological and cognitive biomarkers in smokers and nonsmokers with schizophrenia or schizoaffective disorder. Arch Gen Psychiatry 68: 1195-1206.

Horder J, Browning M, Di Simplicio M, Cowen PJ, Harmer CJ (2012). Effects of 7 days treatment with the cannabinoid type 1 receptor antagonist, rimonabant, on emotional processing. J Psychopharmacol 26: 125-132.
Larson CL, Ruffalo D, Nietert JY, Davidson RJ (2000). Temporal stability of the emotion-modulated startle response. Psychophysiology 37: 92-101.

Laviolette SR, van der Kooy D (2004). The neurobiology of nicotine addiction: bridging the gap from molecules to behaviour. Nat Rev Neurosci 5: 55-65.

Lawrence D, Mitrou F, Zubrick SR (2009). Smoking and mental illness: results from population surveys in Australia and the United States. BMC Public Health 9: 285.

Loughead J, Ray R, Wileyto EP, Ruparel K, Sanborn P, Siegel S et al (2010). Effects of the alpha4beta2 partial agonist varenicline on brain activity and working memory in abstinent smokers. Biol Psychiatry 67: 715-721.

Mannie ZN, Harmer CJ, Cowen PJ, Norbury R (2010). A functional magnetic resonance imaging study of verbal working memory in young people at increased familial risk of depression. Biol Psychiatry 67: 471-477.

Medicines and Healthcare Products Regulatory Agency (2008). Varenicline: safety update. Drug Safety Update 1: 3-4.

Mineur YS, Picciotto MR (2010). Nicotine receptors and depression: revisiting and revising the cholinergic hypothesis. Trends Pharmacol Sci 31: 580-586.

Moore TJ, Furberg CD, Glenmullen J, Maltsberger JT, Singh S (2011). Suicidal behavior and depression in smoking cessation treatments. PLoS One 6: e27016.

National Center for Chronic Disease Prevention and Health Promotion (2011). Tobacco use, targeting the nation's leading killer. http://www.cdc.gov/chronicdisease/resources/publications/ aag/pdf/2011/Tobacco_AAG_2011_508.pdf.

Ohmura Y, Tsutsui-Kimura I, Yoshioka M (2012). Impulsive behavior and nicotinic acetylcholine receptors. J Pharmacol Sci 118: 413-422.

O'Malley SS (2011). Varenicline and the evaluation of neuropsychiatric adverse events in smokers. Biol Psychiatry 69: 1017-1018.

Oncken C, Gonzales D, Nides M, Rennard S, Watsky E, Billing CB et al (2006). Efficacy and safety of the novel selective nicotinic acetylcholine receptor partial agonist, varenicline, for smoking cessation. Arch Intern Med 166: 1571-1577.

Patterson F, Jepson C, Strasser AA, Loughead J, Perkins KA, Gur RC et al (2009). Varenicline improves mood and cognition during smoking abstinence. Biol Psychiatry 65: 144-149.

Patterson F, Jepson C, Loughead J (2010). Working memory deficits predict short-term smoking resumption following brief abstinence. Drug Alcohol Depend 106: 61-64.

Philip NS, Carpenter LL, Tyrka AR, Whiteley LB, Price LH (2009). Varenicline augmentation in depressed smokers: an 8-week, open-label study. J Clin Psychiatry 70: 1026-1031.

Philip NS, Carpenter LL, Tyrka AR, Price LH (2010). Nicotinic acetylcholine receptors and depression: a review of the preclinical and clinical literature. Psychopharmacology (Berl) 212: $1-12$.

Picciotto MR, Zoli M, Rimondini R, Léna C, Marubio LM, Pich EM et al (1998). Acetylcholine receptors containing the beta2 subunit are involved in the reinforcing properties of nicotine. Nature 391: 173-177.

Potter AS, Bucci DJ, Newhouse PA (2012). Manipulation of nicotinic acetylcholine receptors differentially affects behavioral inhibition in human subjects with and without disordered baseline impulsivity. Psychopharmacology (Berl) 220: 331-340.

Pringle A, Browning M, Cowen PJ, Harmer CJ (2011a). A cognitive neuropsychological model of antidepressant drug action. Prog Neuropsychopharmacol Biol Psychiatry 35: 1586-1592.

Pringle A, McTavish SF, Williams C, Smith R, Cowen PJ, Harmer CJ (2011b). Short-term NK1 receptor antagonism and emotional processing in healthy volunteers. Psychopharmacology (Berl) 215: 239-246.

Rey A (1964). L'examen de Clinique en Psychologie. Presses Universitaires de France: Paris. 
Rollema H, Chambers LK, Coe JW, Glowa J, Hurst RS, Lebel LA et al (2007). Pharmacological profile of the alpha4beta2 nicotinic acetylcholine receptor partial agonist varenicline, an effective smoking cessation aid. Neuropharmacology 52: 985-994.

Rokem A, Landau AN, Garg D, Prinzmetal W, Silver MA (2010). Cholinergic enhancement increases the effects of voluntary attention but does not affect involuntary attention. Neuropsychopharmacology 35: 2538-2544.

Sofuoglu M (2010). Cognitive enhancement as a pharmacotherapy target for stimulant addiction. Addiction 105: 38-48.

Spielberger CD, Gorssuch RL, Lushene PR, Vagg PR, Jacobs GA (1983). Manual for the State-Trait Anxiety Inventory. Consulting Psychologists Press: White Bear Lake.

Tapper AR, McKinney SL, Nashimi R, Schwarz J, Deshpande P, Labarca $C$ et al (2004). Nicotine activation of $\alpha 4$ receptors: sufficient for reward, tolerance, and sensitization. Science 306: 1029-1032.

Tonstad S, Davies S, Flammer M, Russ C, Hughes J (2010). Psychiatric adverse events in randomized, double-blind, placebo-controlled clinical trials of varenicline: a pooled analysis. Drug Saf 33: 289-301.

Tsutsui-Kimura I, Ohmura Y, Izumi T, Yamaguchi T, Yoshida T, Yoshioka M (2010). Endogenous acetylcholine modulates impulsive action via alpha4beta2 nicotinic acetylcholine receptors in rats. Eur J Pharmacol 641: 148-153.

von Zerssen D, Petermann F (2011). Bf-SR - Die BefindlichkeitsSkala - Revidierte Fassung. Hogrefe: Göttingen.

Williams JM, Steinberg MB, Steinberg ML, Gandhi KK, Ulpe R, Foulds J (2011). Varenicline for tobacco dependence: panacea or plight? Expert Opin Pharmacother 12: 1799-1812. 